\title{
SMART FERT: APLIKASI PRAKTIS, VALID, DAN MUDAH UNTUK MENGUKUR INDIKATOR FERTILITAS DI ERA OTONOMI DAERAH
}

\author{
Lutfi Agus Salim¹, Hari Kusnanto², Lutfan Lazuardi², dan Kuntoro ${ }^{1}$ \\ ${ }^{1}$ Fakultas Kesehatan Masyarakat, Universitas Airlangga, Surabaya, ${ }^{2}$ Fakultas Kedokteran, \\ Universitas Gadjah Mada, Yogyakarta
}

Korespondensi: Lutfi Agus Salim (e-mail: lutfi.as@fkm.unair.ac.id / lut_unair@yahoo.com)

\begin{abstract}
Abstrak
Indikator fertilitas, seperti Crude Birth Rate (CBR), Total Fertility Rate (TFR), General Fertility Rate (GFR), dan Gross Reproductive Rate (GRR), untuk mengukur kinerja pengendalian penduduk setiap tahun di level kabupaten/kota sejak otonomi daerah sering tidak tersedia. Aplikasi sistem informasi fertilitas Smart Fert sebagai alat untuk mengukur indikator fertilitas yang praktis, valid, dan mudah diaplikasikan sangat layak untuk dikembangkan. Tujuan penelitian ini adalah mengembangkan aplikasi Smart Fert serta menguji hasil perhitungan indikator fertilitas dari aplikasi Smart Fert dibandingkan dengan perhitungan dari hasil Sensus Penduduk 2010. Penelitian ini merancang aplikasi Smart Fert berbasis bahasa visual basic. Untuk mengukur ketepatan dan kevalidan hasil perhitungan fertilitas dari aplikasi Smart Fert, maka hasilnya dibandingkan dengan standar yang baik, yaitu hasil Sensus Penduduk 2010. Hasil penelitian menunjukkan bahwa hasil perhitungan fertilitas dengan aplikasi Smart Fert tidak menunjukkan perbedaan signifikan dengan hasil metode langsung Sensus Penduduk 2010. Dengan demikian, aplikasi Smart Fert dapat dipakai sebagai alat penghitung indikator fertilitas yang praktis, valid, dan mudah diimplementasikan untuk mengukur kinerja pengendalian penduduk di tingkat kabupaten/kota.
\end{abstract}

Kata kunci: Perhitungan Indikator Fertilitas, Aplikasi Smart Fert, Pengendalian Penduduk

\section{SMART FERT: THE PRACTICAL, VALID AND EASY APPLICATION TO MEASURE FERTILITY INDICATORS IN THE ERA OF REGIONAL AUTONOMY}

\begin{abstract}
Fertility indicators, such as Crude Birth Rate (CBR), Total Fertility Rate (TFR), General Fertility Rate (GFR), Gross Reproductive Rate (GRR) to measure the performance of population control each year at the district level since regional autonomy are often unavailable. Smart Fert fertility information system application development as a tool to measure fertility indicators that are practical, valid, easy to apply is very feasible to be made. The purpose of this research is to develop an application and to test the measurement results the fertility indicators by the Smart
\end{abstract}


Fert application compare with the measurement results by 2010 Population Census data. This research is a set of Smart Fert applications based on visual basic language. To check the accuracy of Smart Fert's indirect method, comparison would be made with the measurement results by 2010 Population Census data. The result showed that fertility measurement results by Smart-Fert application was not significantly different with the measurement result by 2010 Population Census data. Thus Smart Fert application could be used as a valid, practical, easy to implement to measure fertility indicators tool to measure the performance of population control at the district/city level.

Keywords: Measurement of Fertility Indicators, Smart Fert application, population control

\section{Pendahuluan}

Indikator fertilitas di tingkat nasional dan provinsi biasanya tersedia dengan baik seiring dengan kegiatan sensus penduduk dan survei, seperti SDKI, Susenas, dan Survei RPJMN. Indikator fertilitas hasil olahan Sensus Penduduk tercatat sangat baik sampai tingkat kabupaten/kota, tetapi kelemahannya adalah Sensus Penduduk dilaksanakan hanya sepuluh tahun sekali. Padahal, dengan diimplementasikannya kebijakan otonomi daerah untuk urusan pengendalian penduduk, sangat mendesak dibutuhkan ketersediaan indikator fertilitas setiap tahun untuk bahan perencanaan dan mengukur kinerja pengendalian penduduk. Namun, pada kenyataannya, indikator fertilitas di tingkat kabupaten/ kota, apalagi tingkat kecamatan sangat jarang tersedia.

Berbagai metode perhitungan fertilitas telah banyak ditemukan oleh banyak ahli demografi dan lembaga kependudukan, baik metode langsung maupun metode tidak langsung, seperti metode Anak Kandung, metode Reverse Survival Ratio, metode Riwayat Kehamilan, dan metode Rele (UN Manual X, 1983), (UN Manual IV, 1967), (Barclay, 1970), (Bogue, 1971), (Iskandar, 1977), (Kasto, 1995), (Nilakusmawati, 2009),
(Lembaga Demografi, 1981). Namun, bagi tingkat kabupaten/kota, dirasakan metode tersebut kurang aplikatif karena berbagai keterbatasan, terutama keterbatasan alat (aplikasi), data, metode dan kemampuan petugas.

Sampai saat ini telah ada software atau aplikasi perhitungan indikator fertilitas yang dikembangkan oleh lembaga internasional, misalnya software Mortpak for Windows (UN, 2003) dan software EastWestPop (East West Center Research Program, 1992). Software tersebut terdiri atas beberapa modul, misalnya untuk menghitung indikator fertilitas dengan software Mortpak for Windows, digunakan modul FERTPF dan FERTCB. Sementara itu, semua modul software EastWestPop digunakan untuk menghitung fertilitas.

Sampai saat ini data registrasi vital kelahiran belum tersedia dengan baik karena kurang sadarnya penduduk melaporkan kelahirannya di awal tahun. Namun, untuk umur di atasnya (umur lima tahunan), data telah tersedia dengan baik sampai tingkat kabupaten/kota, bahkan kecamatan yang dapat dipakai untuk menghitung fertilitas metode tidak langsung. Salah satunya adalah metode Rele, yaitu metode yang memanfaatkan data penduduk lima tahunan, jumlah balita, dan jumlah perempuan usia subur. 
Melihat kondisi di atas, pengembangan aplikasi sistem informasi fertilitas sebagai alat untuk menghitung indikator fertilitas yang praktis, valid, dan mudah diaplikasikan sesuai dengan input data yang tersedia sangat layak untuk dibuat.

Tujuan dari penelitian ini adalah mengembangkan aplikasi Smart Fert dan menguji hasil perhitungan indikator fertilitas dari aplikasi Smart Fert dibandingkan dengan standar yang baik, yaitu perhitungan dari hasil Sensus Penduduk 2010. Apabila didapatkan hasil perhitungan yang valid, maka aplikasi Smart Fert dapat dipakai untuk menghitung indikator fertilitas setiap tahunnya tingkat kabupaten/kota, bahkan tingkat kecamatan.

\section{Tinjauan Pustaka}

\section{Pengukuran Fertilitas Metode Langsung}

Pengukuran fertilitas secaralangsung dapat dilakukan dengan dua cara, yaitu pengukuran fertilitas tahunan dan pengukuran fertilitas kumulatif. Pengukuran fertilitas tahunan maupun pengukuran fertilitas kumulatif samasama menpunyai kelemahan dan keuntungan (Lembaga Demografi, 1981).

\section{a. Crude Birth Rate (CBR)}

Tingkat Kelahiran Kasar adalah perbandingan antara jumlah kelahiran hidup dengan jumlah seluruh penduduk selama setahun per 1.000 penduduk (Lembaga Demografi, 1981).

$$
C B R=\frac{B}{P} \times K:
$$

Keterangan:

$$
\begin{array}{ll}
B= & \text { Jumlah kelahiran } \\
P= & \text { Jumlah penduduk pertengahan } \\
\text { tahun }
\end{array}
$$

Kelemahan dari metode ini adalah semua penduduk dianggap mampu dan dapat melahirkan karena yang menjadi penyebut adalah seluruh penduduk yng meliputi semua umur. Kenyataan menunjukkan bahwa hanya penduduk perempuan saja yang dapat melahirkan dan ini pun masih terbatas pada kelompok umur tertentu.

\section{b. General Fertility Rate (GFR)}

Tingkat kelahiran umur adalah jumlah kelahiran hidup selama setahun per 1.000 penduduk perempuan dalam usia reproduksi umur 15-49 tahun (Lembaga Demografi, 1981).

$$
G F R=\frac{B}{P F_{(15-49)}}
$$

Keterangan:

$$
\begin{aligned}
\mathrm{B} & = \\
P F_{(15-49)}= & \text { jumlah kelahiran } \\
& \text { penduduk perempuan } \\
& \text { usia reproduksi. }
\end{aligned}
$$

Kelemahan metode ini adalah fertilitas dari penduduk perempuan usia reproduksi dianggap sama. Tidak ada variasi fertilitas dari golongan umur tua maupun muda. Dalam kenyataan, fertilitas tahunan berhubungan erat pada struktur umur perempuan.

\section{c. Age Spesific Fertility Rate (ASFR)}

Tingkat fertilitas spesifik menurut umur adalah perbandingan antara jumlah kelahiran hidup per 1.000 penduduk perempuan pada golongan umur tertentu ${ }^{(i)}$ pada usia reproduksi (Lembaga Demografi, 1981).

$$
A S F R=\frac{B_{i}}{P F_{i}} \times K
$$


Keterangan:

$$
\begin{aligned}
B_{i}= & \text { Jumlah kelahiran dari } \\
& \text { kelompok umur (i), misalnya umur } \\
& 20-24 \text { tahun } \\
P F_{i}= & \text { Jumlah penduduk perempuan } \\
& \text { menurut umur (i) dalam usia } \\
& \text { reproduksi, misal umur 20-24 } \\
& \text { tahun. }
\end{aligned}
$$

Dibandingkan dengan ukuran pertama maupun kedua, metode ini lebih spesifik dalam memberikan informasi tentang variasi fertilitas menurut umur. Namun, ukuran fertilitas yang ada atau rata-rata jumlah anak yang dimiliki belum dipisahkan menurut jenis kelamin.

\section{d. Total Fertility Rate (TFR)}

Total Fertility Rate (TFR) adalah rata-rata jumlah anak (laki-laki dan perempuan) yang dilahirkan per 1.000 penduduk permpuan selama masa reproduksi dengan asumsi bahwa tingkat kelahiran tidak mengalami perubahan selama periode reproduksi.

Dalam bentuk rumus dituliskan sebagai berikut (Lembaga Demografi, 1981).

$$
T F R=5 \sum_{i=15-19}^{45=15} A S F R_{i}
$$

TFR adalah lima kali jumlah ASFR (Tingkat Fertilitas menurut Umur). Meskipun dapat memberikan informasi tentang ratarata jumlah anak yang dilahirkan, metode ini belum memberikan gambaran jumlah anak perempuan yang siap menggantikan peran ibunya dalam hal fertilitas. Ini sama halnya dengan ukuran fertilitas menurut golongan umur yang hanya memberikan informasi bahwa fertilitas itu berbeda menurut umur.

\section{e. Gross Reproductive Rate (GRR)}

Gross Reproduction Rate (GRR) dan Net Reproduction Rate (NRR) merupakan ukuran fertilitas yang berkaitan dengan kemampuaan penduduk perempuan melahirkan bayi perempuan untuk menggantikan dirinya bereproduksi. Ukuran yang didapatkan umumnya dinyatakan dengan reproduksi (reproduction), bukan fertilitas (fertility).

Gross Reproduction Rate (GRR) atau tingkat reproduksi bruto adalah jumlah anak perempuan yang dilahirkan hidup per 1.000 penduduk perempuan dengan asumsi bahwa tidak ada bayi perempuan yang meninggal sebelum mengakhiri usia reproduksi.

Dalam bentuk rumus dituliskan sebagai berikut (Lembaga Demografi, 1981).

$$
G R R=5 \sum_{i=15-19}^{45=15} A S F R_{F i},
$$

Catatan: Notasi Fi berarti kelahiran bayi perempuan

\section{f. Net Reproductive Rate (NRR)}

Tingkat Reproduksi Neto adalah jumlah anak perempuan yang dilahirkan per 1.000 penduduk perempuan dengan mempertimbangkan kemungkinan bayi tersebut meninggal dalam usia reproduksi. Dikatakan reproduksi neto karena ukuran ini telah mempertimbangkan kemungkinan meninggal. Berbeda halnya dengan Reproduksi Bruto (GRR), kemungkinan meninggal dari bayi perempuan tersebut belum dipertimbangkan. Dalam ukuran reproduksi neto ini, kemungkinan meninggal dihitung menggunakan Tabel Kematian dengan rumus sebagai berikut (Lembaga Demografi, 1981). 


$$
N R R \sum_{i=15-19}^{45=15} A S F R_{F i} \times \frac{5 \mathrm{I}_{x}}{10}
$$

\section{Pengukuran Fertilitas Metode Tidak Langsung}

\section{a. Metode Anak Kandung}

Metode anak kandung atau lebih dikenal dengan own children diperkenalkan pertama kali oleh W.H. Grabill dan diperbaiki bersama Lee-Jay Cho dan Choe (1986). Dasar asumsi perkiraan fertilitas dengan metode Survival Ratio, yaitu memperkirakan angka fertilitas sebelum sensus atau survai kependudukan dilakukan atas dasar tabulasi dari anakanak yang tinggal bersama ibunya pada saat pencacahan atau pendataan yang dilakukan.

Berikut adalah tiga tahap perhitungan.

1. memperkirakan jumlah kelahiran dalam setahun, dengan dengan cara Reverse Survival Ratio dari anak-anak berumur 0-4 atau 0-14 tahun

2. memperkirakan rata-rata jumlah penduduk perempuan pada pertengahan tahun, yaitu rata-rata dari jumlah penduduk menurut sensus atau survei dan perkiraan jumlah penduduk 15 tahun sebelum sensus atau survei

3. memperkirakan angka kelahiran menurut umur (ASFR) yang diperoleh dari hasil pembagian perkiraan jumlah kelahiran dan rata-rata jumlah penduduk perempuan.

Keunggulan dari metode anak kandung adalah perkiraan angka kelahiran (ASFR) dapat dirinci menurut umur tahunan dan tidak memerlukan banyak informasi/data. Informasi pokok yang diperlukan adalah jumlah anak tinggal bersama ibunya menurut umur. Di samping itu, beberapa kelemahan yang perlu diperhatikan adalah kealpaan/lupa tentang jumlah anak dan kesalahan pelaporan umur. Selanjutnya mortalitas, terutama mortalitas anak, dapat juga berpengaruh terhadap hasil perkiraan fertilitas. Sejalan dengan kelemahan ini, untuk mendapatkan perkiraan angka fertilitas yang baik diperlukan penyesuaian yang harus dilakukan sesuai dengan kelemahan data dasar yang digunakan.

\section{b. Metode Reverse Survival Ratio}

Dasar asumsi perkiraan fertilitas dengan metode Reverse Survival Ratio adalah penduduk usia 0-14 tahun berasal dari kelahiran selama ini sampai lima tahun lalu. Misalnya, penduduk usia 4 tahun adalah mereka yang berasal dari lima tahun yang lalu, penduduk usia 3 tahun berasal dari kelahiran empat tahun lalu, dan seterusnya. Dengan demikian, perkiraan fertilitas didasarkan pada komposisi umur penduduk, khususnya penduduk perempuan. Metode estimasi ini sangat tergantung kualitas data komposisi umur penduduk. Oleh karena itu, sebelum data digunakan, komposisi umur penduduk sebaiknya dirapikan dulu untuk mengurangi kesalahan yang ada.

Tahap-tahap perkiraan angka fertilitas adalah sebagai berikut :

1. menghitung penduduk perempuan usia subur untuk rentang waktu sebelum sensus atau survai dilakukan

2. menghitung jumlah penduduk perempuan tengah periode

3. menghitung indeks fertilitas dan proporsi penduduk perempuan yang statusnya nikah. Indeks fertilitas alami dapat diperoleh dari buku manual (UN Manual IV, 1967) atau pola yang lain bila datanya tersedia.

4. menghitung penduduk perempuanyang ditimbang dengan cara mengalikan jumlah penduduk perempuan tengah 
periode dengan faktor penimbangan pada setiap umur yang sama

5. Indeks fertilitas dapat dihitung dengan cara jumlah penduduk kelahiran selama lima tahun dibagi dengan jumlah penduduk perempuan tertimbang.

\section{c. Metoda Riwayat Kehamilan}

Untuk mengatasi berbagai hambatan maupun ketidakcermatan pengumpulan data fertilitas serta untuk menghemat tenaga, biaya, dan waktu, Singuefield (1978) dalam (Kasto, 1995) telah menawarkan metode baru untuk memperkirakan fertilitas. Metode estimasi fertilitas ini dinamakan pregnancy status atau metode status kehamilan dari Singuefield, yang digunakan untuk memperkirakan angka kelahiran. Cara ini dianggap cukup sederhana, biayanya murah, dan hasilnya lebih cermat. Asumsi dasar dari metode status kehamilan adalah apabila perempuan yang hamil, ia mengetahui bahwa dirinya sedang hamil dan mengetahui pula lama (minggu atau bulan) kehamilannya. Dari semua kehamilan ini diasumsikan akan berakhir dengan menghasilkan lahir hidup.

Kelemahan dari metode ini adalah apabila ada sebagian dari perempuan yang hamil tidak mengetahui bahwa dirinya sedang hamil. Ini dapat terjadi pada kehamilan usia muda, terutama kurang dari dua bulan. Dapat saja mereka belum mengetahui bahwa dirinya telah hamil. Untuk itu, diperlukan angka penyesuaian agar usia kehamilan muda tidak kekurangan cacah. Kemudian diperlukan pula angka penyesuaian untuk kehamilan yang tidak mengasilkan lahir hidup meskipun proporsinya semakin kecil. Kemajuan di bidang pangan dan gizi akan menekan proporsi bayi lahir mati. Faktor ini dapat diabaikan karena proporsinya semakin sedikit.
Keuntungan dari model estimasi ini adalah datanya yang dikumpulkan sangat sederhana dan mudah untuk dijawab. Apakah ibu sedang hamil?. Bila sedang hamil, telah berapa minggu atau bulan? Kecermatan data ini terjamin dari responden karena ia dapat mengingatingat kembali tentang urutan kelahiran pada anak-anak yang masih hidup maupun telah meninggal. Karena pertanyaannya sangat sederhana, maka proses pengumpulan data di lapangan relatif singkat dan dapat menyajikan data dalam waktu singkat pula untuk tahun yang bersangkutan.

Angka penyesuaian yang dapat dilakukan adalah distrribusi kekurangan cacah perempuan hamil, terutama kehamilan usia muda. Jika data yang dikumpulkan cukup lengkap, maka angka penyesuian kekurangan cacah dapat dihitung untuk setiap bulan. Akan tetapi, bila datanya kurang tersedia, dapat dilakukan untuk setiap kelompok. Apabila ingin mendapatkan angka perkiraan yang lebih baik, maka angka penyesuaian sebaiknya dilakukan pula untuk kegagalan kehamilan, yakni kehamilan yang tidak diakhiri dengan lahir hidup. Dalam hal ini, pelaporan umum responden juga perlu dievaluasi.

Adioetomo dalam (Kasto, 1995) menggunakan asumsibahwa distribusi bulan kehamilan dianggap merata dari bulan ke-1 sampai 9 sehingga kekurangan cacah perempuan hamil pada bulan kehamilan. Sejalan dengan itu, diperlukan angka penyesuaian untuk bulan kehamilan. Rata-rata kehamilan dianggap 9 bulan sehingga angka penyesuaian dapat diperkirakan sesuai dengan kekurangan tersebut.

Parameter fertilitas biasanya tidak dinyatakan dalam bulan, tetapi dinyatakan dalam tahun. Sejalan dengan ini, maka angka penyesuaian dihitung dengan rumus 12/9, yaitu sembilan bulan kehamilan dari dua belas bulan. Dengan demikian, angka pemikiran angka penyesuian seperti berikut. 


$$
\mathrm{AP}=\frac{B K}{B K-\left({ }_{n} K C_{i}+{ }_{n} K C_{i+3}+{ }_{n} K C_{i+6}\right)} \times \frac{12}{\mathrm{BK}}
$$

Keterangan:

$$
\begin{aligned}
& \mathrm{AP}=\text { Angka penyesuaian } \\
& \mathrm{BK} \text { = Rata-rata lama kehamilan, } \\
& \text { diasumsikan selama } 9 \text { bulan } \\
& { }_{n} \mathrm{KC}_{1}=\text { Kekurangan cacah kehamilan }
\end{aligned}
$$

\section{d. Metode Rele}

Menurut metode Rele dalam Kasto (1995) dan juga dalam Nilakusmawati (2009), pada hampir semua populasi dapat dijumpai hubungan linear antara rasio ibu anak (child women ratio) dengan tingkat kelahiran kasar (Gross Reproduction Rate) yang kemudian dapat diubah menjadi tingkat kelahiran total TFR (Total Fertility Rate).

Keuntungan utama dari metode ini adalah kesederhanaannya karena hanya memerlukan sebaran umur penduduk dan perkiraan kematian. Berdasarkan komposisi penduduk menurut umur dan jenis kelamin, dapat dihasilkan rasio ibu-anak. Dengan mengetahui perkiraan kasar atas harapan hidup saat lahir, jumlah ini dapat diubah menjadi perkiraan TFR. Dengan demikian, metode ini menghasilkan suatu cara yang cepat dan mudah dalam memperkirakan kelahiran. Kebutuhan data terbatas pada persebaran penduduk menurut umur dan jenis kelamin, serta indikasi tentang tingkat mortalitas dalam bentuk angka harapan hidup saat lahir. Tabulasi umur dan jenis kelamin boleh dikatakan selalu tersedia pada survei yang dilakukan oleh BPS, seperti SP, Supas, dan Susenas. Dengan demikian, CWR selalu dapat dihitung di setiap kecamatan, kabupaten/kota, dan provinsi.

Kelemahannya adalah metode ini sensitif terhadap perbedaan tingkat lewat cacah antara ibu dan anak. Selain itu, dalam perhitungannya diperlukan informasi tentang tingkat kematian. Rele mendasarkan diri pada konsep penduduk stabil (stable population). Prinsip yang menjadi dasar konsep penduduk stabil adalah jika pengaruh migrasi internasional terhadap suatu penduduk suatu negara dapat diabaikan, maka komposisi umur penduduk merupakan akibat dari kecenderungan fertilitas dan mortalitas di masa lalu.

Langkah pertama adalah menghitung child woman ratio (CWR) dengan salah satu rumus sebagai berikut.

$$
\begin{aligned}
& \text { CWR1 = } \frac{\text { P0-4 }}{\text { W15-44 }} \\
& \text { CWR 2 = } \frac{\text { P0-4 }}{\text {------- }}
\end{aligned}
$$




$$
\begin{aligned}
& \text { CWR } 3=\frac{\text { P5-9 }}{\text { W20-49 }} \\
& \text { CWR } 4=\frac{\text { P5-9 }}{\text { W20-54 }}
\end{aligned}
$$

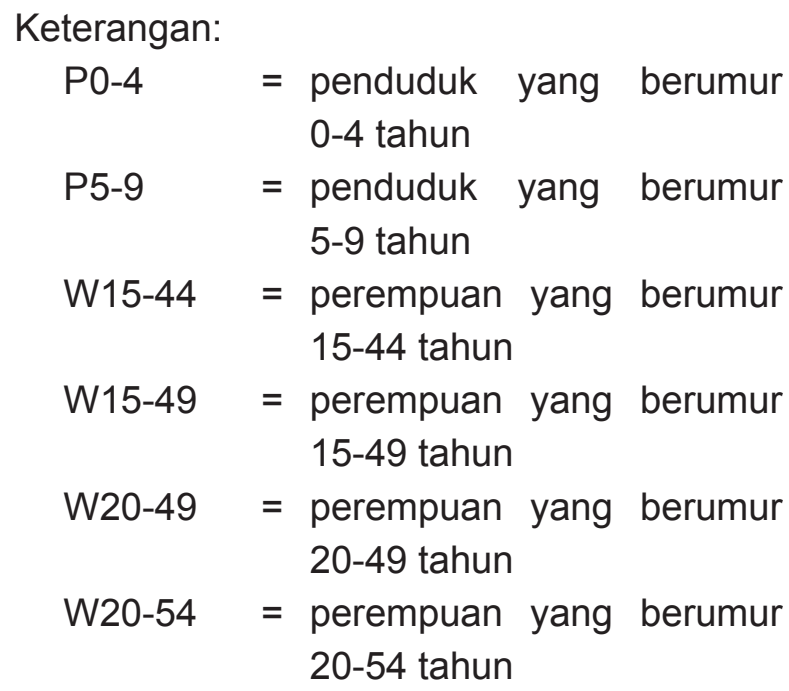

Rele (1967) telah menghitung serangkaian faktor pengali yang dirinci menurut tingkat kematian yang dapat dipakai untuk merubah CWR menjadi GRR (Gross Reproduction Rate) dan TFR (Total Fertility Rate). Seperti halnya dalam metode reverse dan anak kandung, terlebih dulu harus diketahui mortality level yang biasanya dihitung dengan metode Brass (1968) atau modifikasinya berdasarkan ratarata anak yang pernah dilahirkan dan yang masih hidup (Kasto, 1995).

\section{Pengembangan Sistem Informasi}

Dalam pengembangan sistem informasi proses utama untuk menggambarkan langkah-langkahnya, digunakan siklus hidup pengembangan sistem (systems development life cycle) (Yakub, 2012). Systems development life cycle memiliki fase-fase tertentu yang setiap fasenya

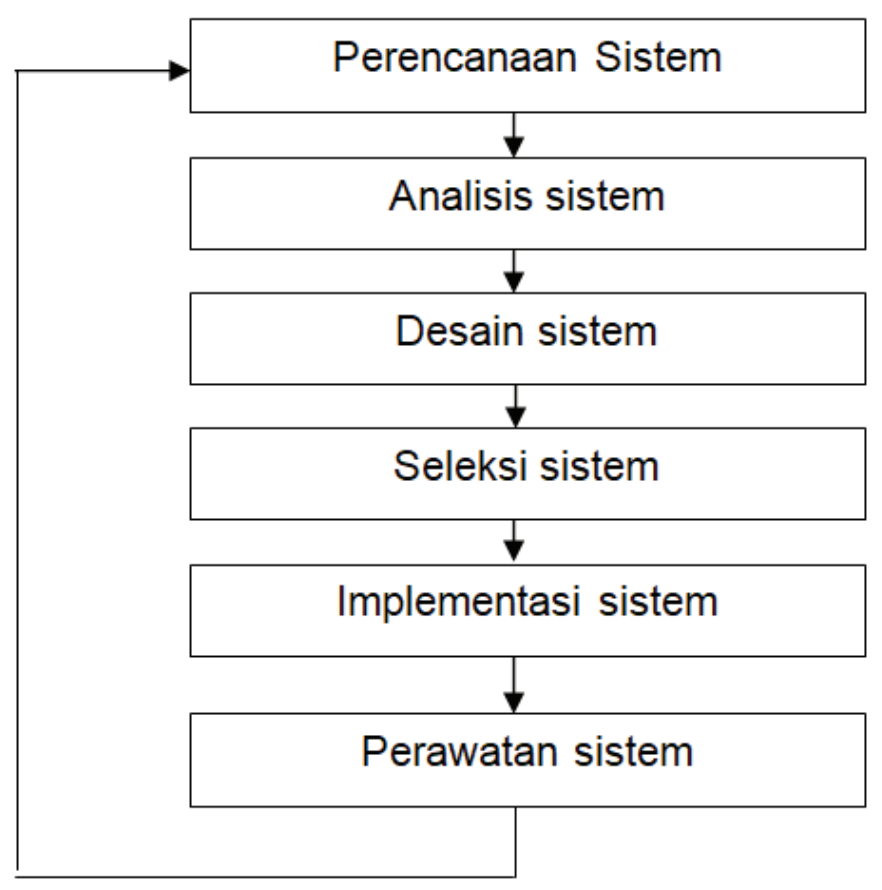

Sumber: Jogiyanto (2005)

Gambar 1 Siklus Hidup Pengembangan Sistem 
memiliki karakteristik tersendiri. Tahapan dari siklus hidup pengembangan sistem (systems development life cycle) terdiri atas tahap perencanaan sistem (systems planning), analisis sistem (systems analysis), desain sistem (system designs), seleksi sistem (systems selection), implementasi sistem (systems implementation), dan perawatan sistem (systems mantenance) (Jogiyanto, 2005).

Pengembangan sistem (system development) dapat berarti menyusun suatu sistem yang baru untuk menggantikan sistem yang lama secara keseluruhan atau memperbaiki sistem yang telah ada.

Tahap perancangan sistem mempunyai dua tujuan utama, yaitu untuk menggambarkan kebutuhan informasi para pemakai sistem serta memberikan rancang bangun kepada pemogram komputer dan ahli lainnya (Jogiyanto, 2009). Perencanaan sistem mencakup keseluruhan unit bisnis maupun seluruh seluruh departemen dengan memperhatikan tujuan dari unit bisnis perusahaan (Yakub, 2012).

Sementara itu, ada dua tujuan perancangan sistem (Jogiyanto, 2009), yaitu perancangan sistem secara logika (logical system design) atau perancangan sistem secara umum (general system design) dan perancangan sistem secara terinci (detail system design). Tujuan dari perancangan sistem secara umum adalah memberikan gambaran secara umum tentang suatu perancangan sistem. Hal ini akan membantu untuk lebih mengefisiensi dana jika rancangan sistem tidak disetujui untuk diterapkan karena perancangan sistem masih bersifat umum (Jogiyanto, 2009).

Perancangan sistem secara terinci atau perancangan sistem fisik adalah tahap lanjutan dari perancangan sistem secara umum karena memberikan gambaran komponen-komponen sistem dan digunakan untuk menggambarkan secara fisik komponen-komponen sistem yang akan dibangun (Jogiyanto, 2009).

Fase perancangan sistem harus memperhatikan faktor-faktor kelayakan dan faktor-faktor strategis. Menurut Jogiyanto (2005), faktor-faktor kelayakan menilai apakah sistem informasi yang dikembangkan akan mampu memenuhi tujuan organisasi. Faktor kelayakan (feasibility factors) terdiri atas kelayakan teknis, ekonomis, legal, operasional, dan kelayakan rencana. Studi kelayakan ini biasanya dilakukan oleh seorang analis sistem. Sementara itu, faktorfaktor strategis terdiri atas produktivitas, diferensiasi, dan manajemen. Faktor strategis berkaitan dengan pendukung sistem informasi dari sasaran bisnis dipertimbangkan untuk setiap proyek yang diusulkan.

Analisis sistem (system analysis) (Jogiyanto, 2005) dapat didefinisikan sebagai penguraian dari suatu sistem informasi yang utuh ke dalam bagian-bagian komponennya. Maksud dari penguraian itu adalah untuk mengidentifikasikan dan mengevaluasi permasalahan, kesempatan, hambatan yang terjadi, dan kebutuhan yang diharapkan sehingga dapat diusulkan perbaikannya.

Tahap analisis sistem terdiri atas kegiatankegiatan sebagai berikut (Jogiyanto, 2009).

1. Studi pendahuluan, yaitu kegiatan awal dari analisis sistem yang memberikan gambaran mengenai ruang lingkup dan pemahaman awal dari pembangunan sistem informasi

2. Studi kelayakan (feasibility study) dalam analisis sistem sama dengan dalam perancanaan sistem namun dalam perencanaan sistem yang dipaparkan oleh Jogiyanto (2009) terdiri atas lima macam kelayakan yaitu kelayakan teknologi, kelayakan ekonomis, kelayakan legal, kelayakan operasi, dan studi kelayakan sosial. 
3. mengidentifikasi permasalahan dan kebutuhan informasi pemakai

4. memahami sistem yang ada

5. menganalisis hasil penelitian.

Setelah sistem selesai dirancang, maka tahap berikutnya adalah implementasi sistem dan pada tahap ini sistem siap dioperasikan. Tahap implementasi sistem terdiri atas beberapa kegiatan sebagai berikut (Jogiyanto, 2005).

1. mempersiapkan rencana implementasi

2. melakukan kegiatan implementasi, di antaranya memilih dan melatih orangorang yang akan mengoperasikan sistem, memilih dan mempersiapkan lokasi penempatan sistem, mengujicobakan sistem, serta konversi sistem

3. menindaklanjuti implementasi.

Dalam tahap implementasi sistem, dibutuhkan sebuah proses untuk menggantikan sistem yang lama dengan sistem yang baru. Menurut Jogiyanto (2009), hal ini dapat dilakukan dengan konversi sistem. Berbagai macam konversi sistem adalah sebagai berikut.

1. Konversi paralel adalah pemodel pengonversian dengan mengoperasikan sistem yang baru bersamaan dengan sistem yang lama dalam periode waktu yang sama. Kedua sistem dioperasikan secara bersama untuk melihat kesuksesan atau kegagalan pengimplementasian sistem baru yang menggantikan sistem yang lama (Yakub, 2012). Kelebihan konversi paralel adalah apabila penerapan sistem baru mengalami kegagalan, maka sistem lama masih berjalan, tetapi penerapan sistem ini membutuhkan biaya yang lebih mahal (Jogiyanto, 2009).
2. Konversi pilot atau konversi lokasi (location conversion) dilakukan bertahap dari satu lokasi ke lokasi lain atau dari satu departemen ke departemen lain hingga sistem informasi terimplementasi dengan sempurna. Jadi dalam penerapan sistem ini, pengimplementasian sistem dapat dievaluasi dari lokasi sebelumnya agar lokasi berikutnya dapat terimplementasi dengan baik (Jogiyanto, 2009)

3. Konversi bertahap (phasing conversion atau stepped conversion atau staged conversion atau phasein conversion atau phased cutover conversion) dilakukan dengan mengimplementasikan sistem tahap demi tahap per modul. Kelebihan dari sistem ini adalah risiko kegagalannya tidak terlalu tinggi karena diterapkan per modul. Sementara itu, kekurangannya adalah membutuhkan waktu yang relatif lama.

4. Konversi langsung (direct conversion atau direct cutover atau cold turkey conversion atau abrupt cutover) adalah penggantian pengimplementasian secara langsung dari sistem yang lama ke sistem yang baru sehingga biayanya tidak terlalu besar, tetapi risiko kegagalan sangat tinggi karena sistem lama telah benar-benar dikonversi.

Yang terakhir adalah operasi dan perawatan sistem. Menurut Jogiyanto (2009), jika sistem telah dioperasikan, maka harus ada perawatan lebih lanjut. Tahap ini disebut operasi dan perawatan sistem (system operation and maintenance). Sistem perlu dirawat karena sistem mengandung kesalahan-kesalahan yang perlu terus diperbaiki, juga dapat karena perubahan kebutuhan terhadap sistem 
yang digunakan, perubahan sistem karena perubahan lingkungan ekstern, dan perlunya peningkatan sistem informasi sesuai dengan kompleksitas zaman.

\section{Metode Penelitian}

Penelitian ini merupakan penelitian explanatory, yaitu penelitian yang bertujuan untuk menguji hipotetis penelitian. Sementara itu, hipotesis penelitian ini adalah ada tidaknya perbedaan antara hasil olahan Smart Fert dengan metode langsung olahan data Sensus Penduduk 2010. Populasinya adalah kabupaten/kota di Provinsi Jawa Timur sehingga unit analisisnya adalah kabupaten/ kota.

Bahan yang dipakai dalam penelitian ini adalah seperangkat aplikasi Smart Fert (dengan bahasa visual basic), software excell untuk mengecek kebenaran perhitungan metode tidak langsung Smart Fert, seperangkat paket program SPSS untuk menilai kesesuaian hasil olahan Smart Fert dengan olahan BPS data Sensus Penduduk 2010.

Analisis statistik yang digunakan pada penelitian ini adalah dengan uji perbedaan sampel independen (independent $t$ test) untuk menguji kesesuaian antara hasil olahan Smart Fert dengan hasil pengukuran fertilitas Sensus Penduduk 2010.

\section{Hasil Penelitian}

Pengembangan Sistem Informasi Smart Fert

Aplikasi Smart Fert dirancang dan dikembangkan dengan bahasa visual basic dan dapat dioperasikan dengan program windows. Penampilan dan keluaran hasil dari aplikasi Smart Fert telah dicek kesesuaiannya dengan perhitungan dengan program excel.

Menu yang dikembangkan terdiri atas sepuluh menu perhitungan indikator fertilitas, baik metode langsung maupun metode tidak langsung sebagai berikut.

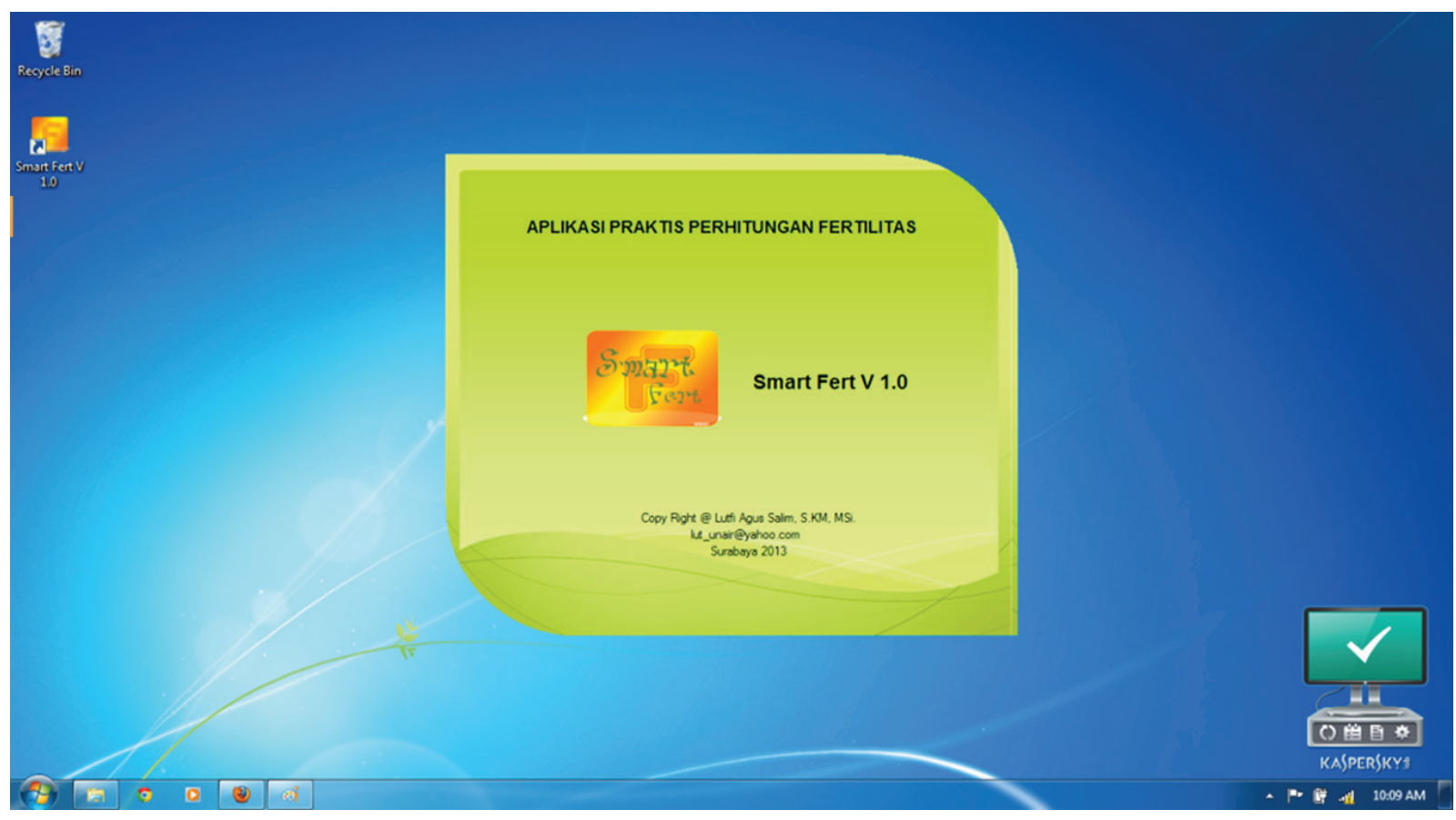




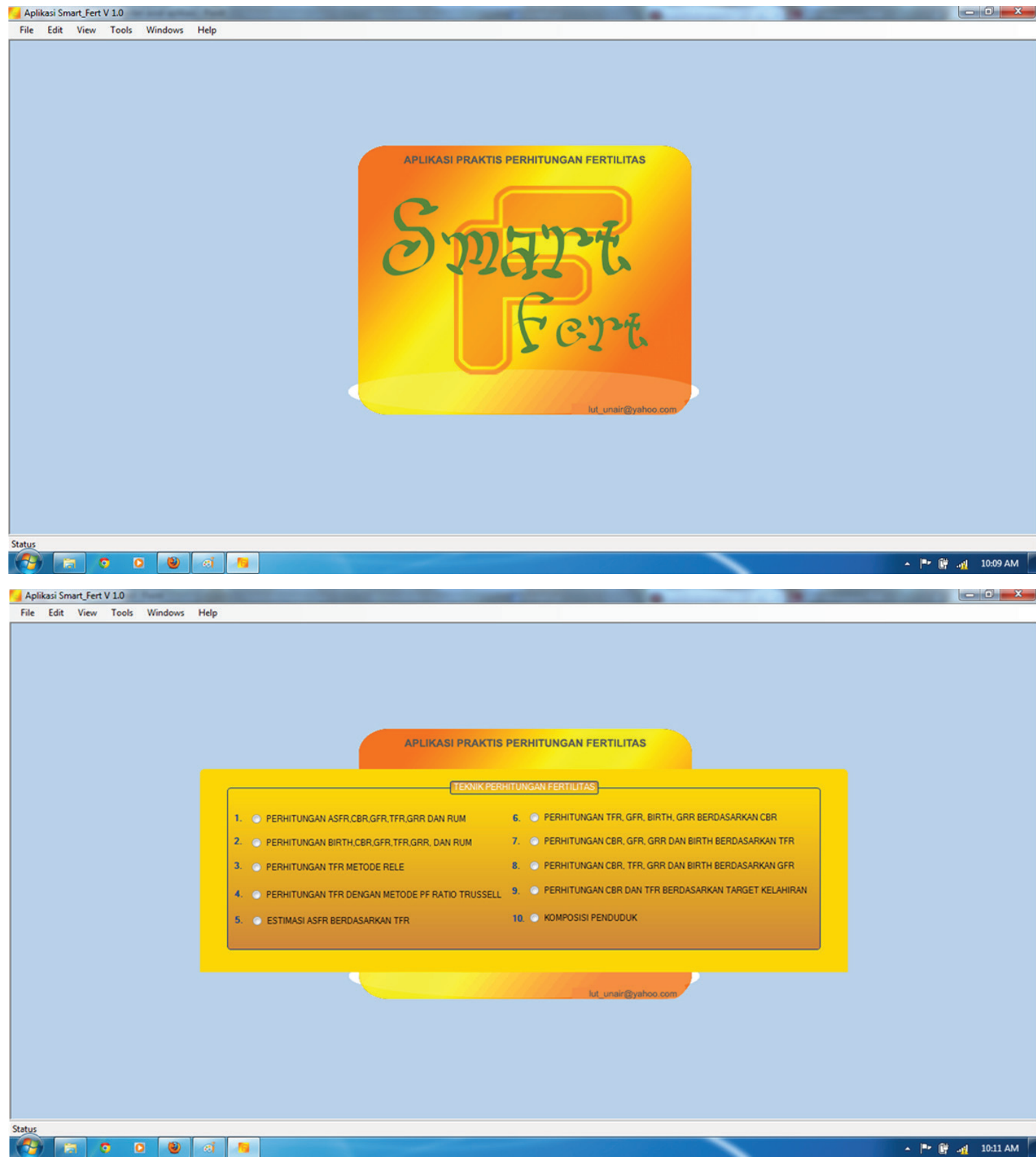

Menu 1 : Perhitungan ASFR, CBR, GFR, TFR, GRR dan RUM

Menu 2 : Perhitungan Birth, CBR, GFR, Menu 7 : Perhitungan CBR, GFR, GRR dan TFR, GRR dan RUM

Menu 3 : Perhitungan TFR metode RELE

Menu 4 : Perhitungan TFR dengan metode PF ratio Trussell

Menu 5 : Estimasi ASFR berdasarkan TFR
Menu 6 : Perhitungan TFR, GFR, Birth, GRR berdasarkan CBR Birth berdasarkan TFR

Menu 8 : Perhitungan CBR, TFR, GRR dan Birth berdasarkan GFR

Menu 9 : Perhitungan CBR dan TFR berdasarkan target kelahiran

Menu 10 : Komposisi Penduduk 
Untuk setiap menu, akan ditampilkan informasi mengenai input dan output-nya. Hasil perhitungannya dapat langsung dilihat di menu tampilan atau dapat disimpan juga di program excell. Informasi mengenai instalasi, menjalankan seluruh menu di aplikasi Smart Fert dapat dibaca petunjuk penggunaan aplikasi Smart Fert tersendiri.

Kesesuaian Hasil Olahan Aplikasi Smart Fert dengan Hasil Sensus Penduduk 2010

Untuk melihat kesesuaian antara hasil olahan aplikasi Smart Fert dan metode langsung Sensus Penduduk 2010, dilakukan uji perbedaan antara hasil kedua metode tersebut. Indikator yang akan dibandingkan adalah indikator Total Fertility Rate (TFR), General Fertility Rate (GFR), dan Crude Birth Rate (CBR).
Hasil Perhitungan Angka Kelahiran Total (Total Fertility Rate/TFR)

Total Fertility Rate (TFR) adalah rata-rata jumlah anak (laki-laki dan perempuan) yang dilahirkan oleh perempuan selama masa reproduksinya. Ukuran fertilitas ini adalah ukuran yang sangat penting untuk mengetahui keberhasilan pengendalian penduduk di suatu daerah.

Bila menggunakan metode langsung, maka TFR dihitung dari penjumlahan dari total kelahiran yang dirinci menurut kelompok umur perempuan (ASFR). Karena sistem administrasi saat ini belum baik, maka ASFR tidak didapatkan setiap tahun.

Salah satu metode tidak langsung dalam menghitung TFR adalah metode Rele, dengan input data yang utama adalah CWR (Child Woman Ratio) serta kebutuhan data balita dan data perempuan usia subur. Data balita dan perempuan usia subur ini didapatkan sampai tingkat kecamatan untuk setiap tahunnya.
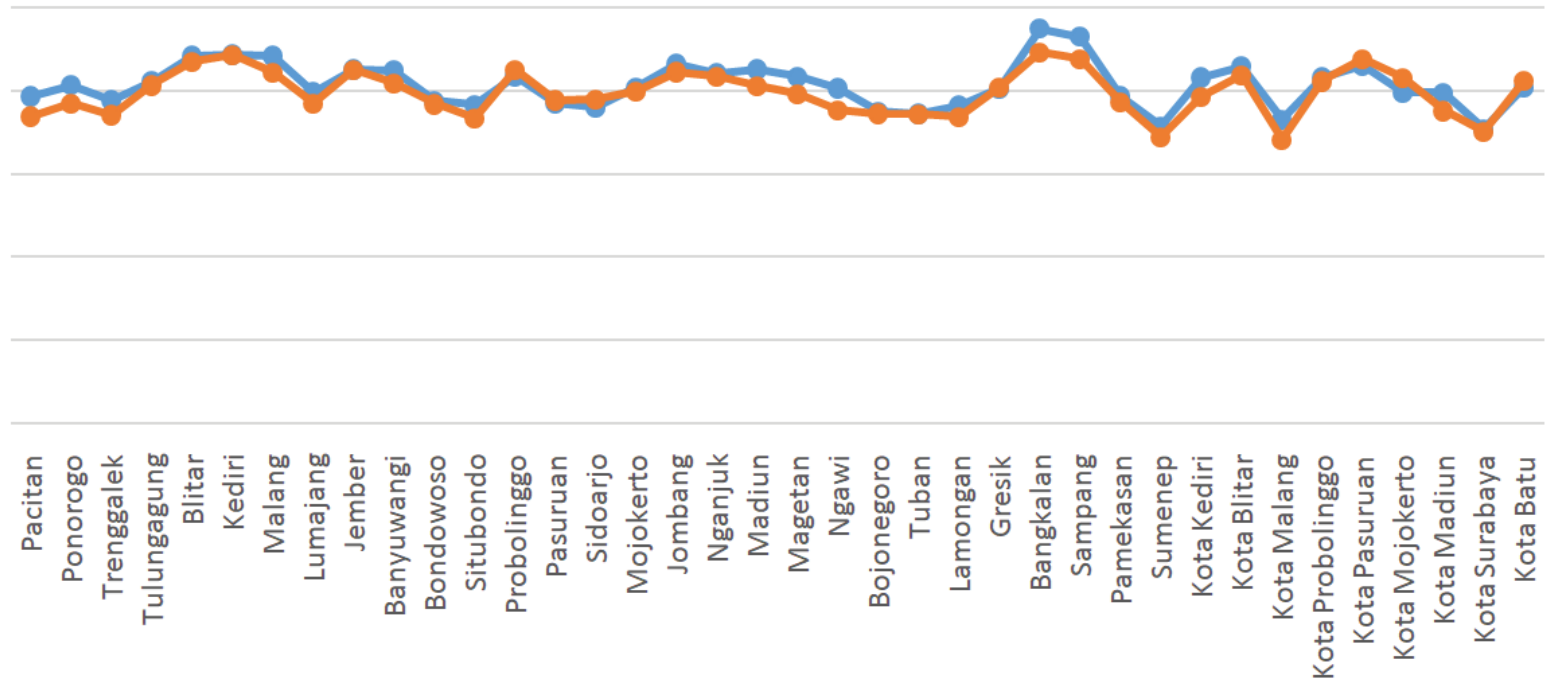

-TFR METODE LANGSUNG —TFR SMARTFERT

Gambar 2 TFR Hasil Olahan Smart Fert dan Sensus Penduduk 2010 
Tabel 1 TFR Hasil Olahan Aplikasi Smart Fert dan Sensus Penduduk 2010

\begin{tabular}{|c|c|c|c|c|}
\hline & Kab/Kota & $\begin{array}{c}\text { TFR } \\
\text { Metode Langsung } \\
\text { (Data SP 2010) }\end{array}$ & $\begin{array}{c}\text { TFR } \\
\text { Metode Rele dengan } \\
\text { Aplikasi Smart Fert } \\
\text { (Data SP 2010) }\end{array}$ & Selisih \\
\hline & Kabupaten & & & \\
\hline 1 & Pacitan & 1,969 & 1,846 & 0,123 \\
\hline 2 & Ponorogo & 2,036 & 1,923 & 0,113 \\
\hline 3 & Trenggalek & 1,944 & 1,855 & 0,089 \\
\hline 4 & Tulungagung & 2,061 & 2,034 & 0,027 \\
\hline 5 & Blitar & 2,211 & 2,177 & 0,034 \\
\hline 6 & Kediri & 2,219 & 2,215 & 0,004 \\
\hline 7 & Malang & 2,213 & 2,110 & 0,103 \\
\hline 8 & Lumajang & 1,993 & 1,927 & 0,066 \\
\hline 9 & Jember & 2,131 & 2,126 & 0,005 \\
\hline 10 & Banyuwangi & 2,126 & 2,048 & 0,078 \\
\hline 11 & Bondowoso & 1,941 & 1,920 & 0,021 \\
\hline 12 & Situbondo & 1,917 & 1,837 & 0,080 \\
\hline 13 & Probolinggo & 2,091 & 2,126 & $-0,035$ \\
\hline 14 & Pasuruan & 1,930 & 1,944 & $-0,014$ \\
\hline 15 & Sidoarjo & 1,900 & 1,946 & $-0,046$ \\
\hline 16 & Mojokerto & 2,022 & 1,997 & 0,025 \\
\hline 17 & Jombang & 2,164 & 2,115 & 0,049 \\
\hline 18 & Nganjuk & 2,107 & 2,085 & 0,022 \\
\hline 19 & Madiun & 2,130 & 2,027 & 0,103 \\
\hline 20 & Magetan & 2,089 & 1,980 & 0,109 \\
\hline 21 & Ngawi & 2,018 & 1,883 & 0,135 \\
\hline 22 & Bojonegoro & 1,878 & 1,863 & 0,015 \\
\hline 23 & Tuban & 1,865 & 1,859 & 0,006 \\
\hline 24 & Lamongan & 1,913 & 1,845 & 0,068 \\
\hline 25 & Gresik & 2,015 & 2,025 & $-0,010$ \\
\hline 26 & Bangkalan & 2,376 & 2,233 & 0,143 \\
\hline 27 & Sampang & 2,329 & 2,196 & 0,133 \\
\hline 28 & Pamekasan & 1,969 & 1,930 & 0,039 \\
\hline \multirow[t]{2}{*}{29} & Sumenep & 1,789 & 1,719 & 0,070 \\
\hline & Kota & & & \\
\hline 30 & Kota Kediri & 2,083 & 1,965 & 0,118 \\
\hline 31 & Kota Blitar & 2,151 & 2,097 & 0,054 \\
\hline 32 & Kota Malang & 1,829 & 1,705 & 0,124 \\
\hline 33 & Kota Probolinggo & 2,082 & 2,058 & 0,024 \\
\hline 34 & Kota Pasuruan & 2,156 & 2,196 & $-0,040$ \\
\hline 35 & Kota Mojokerto & 1,990 & 2,076 & $-0,086$ \\
\hline 36 & Kota Madiun & 1,992 & 1,880 & 0,112 \\
\hline 37 & Kota Surabaya & 1,773 & 1,753 & 0,020 \\
\hline \multirow[t]{2}{*}{38} & Kota Batu & 2,022 & 2,063 & $-0,041$ \\
\hline & JATIM & 2,011 & 2,006 & 0,005 \\
\hline
\end{tabular}

Sumber: Data primer, 2013. 
TFR hasil olahan Smart Fert dan metode langsung dari Sensus Penduduk dapat dilihat pada Gambar 2.

Berdasarkan uji t-test untuk membedakan antara TFR hasil Smart Fert dengan TFR metode langsung data Sensus Penduduk di 38 kabupaten/kota di Jawa Timur, didapatkan hasil tidak signifikan (Sig. $=0,132)$. Hal ini berarti tidak ada perbedaan signifikan antara kedua metode perhitungan TFR.

Hasil Perhitungan Angka Kelahiran Umum (General Fertility Rate/GFR)

General Fertility Rate (GFR) adalah jumlah kelahiran per 1.000 perempuan usia reproduktif secara total tanpa dirinci menurut usia.
Bila menggunakan metode langsung, maka GFR dihitung dari jumlah kelahiran dibagi dengan jumlah perempuan usia subur. Perlu diketahui bahwa sampai saat ini pelaporan rutin mengenai jumlah kelahiran setiap tahunnya belum baik. Di Dinas Kependudukan Kabupaten/Kota, data jumlah yang lahir adalah jumlah yang mengurus akta kelahiran, padahal jumlah yang mengurus akta kelahiran selalu lebih sedikit daripada jumlah kelahiran.

Dalam metode tidak langsung, GFR di aplikasi Smart Fert ini dihitung menggunakan metode asosiasi dengan memanfaatkan data CWR dan TFR hasil perhitungan metode Rele. Input data ini mudah didapatkan karena pendataan balita dan perempuan usia subur telah dilakukan secara rutin.

GFR dari olahan kedua metode dapat dilihat pada Gambar 3.

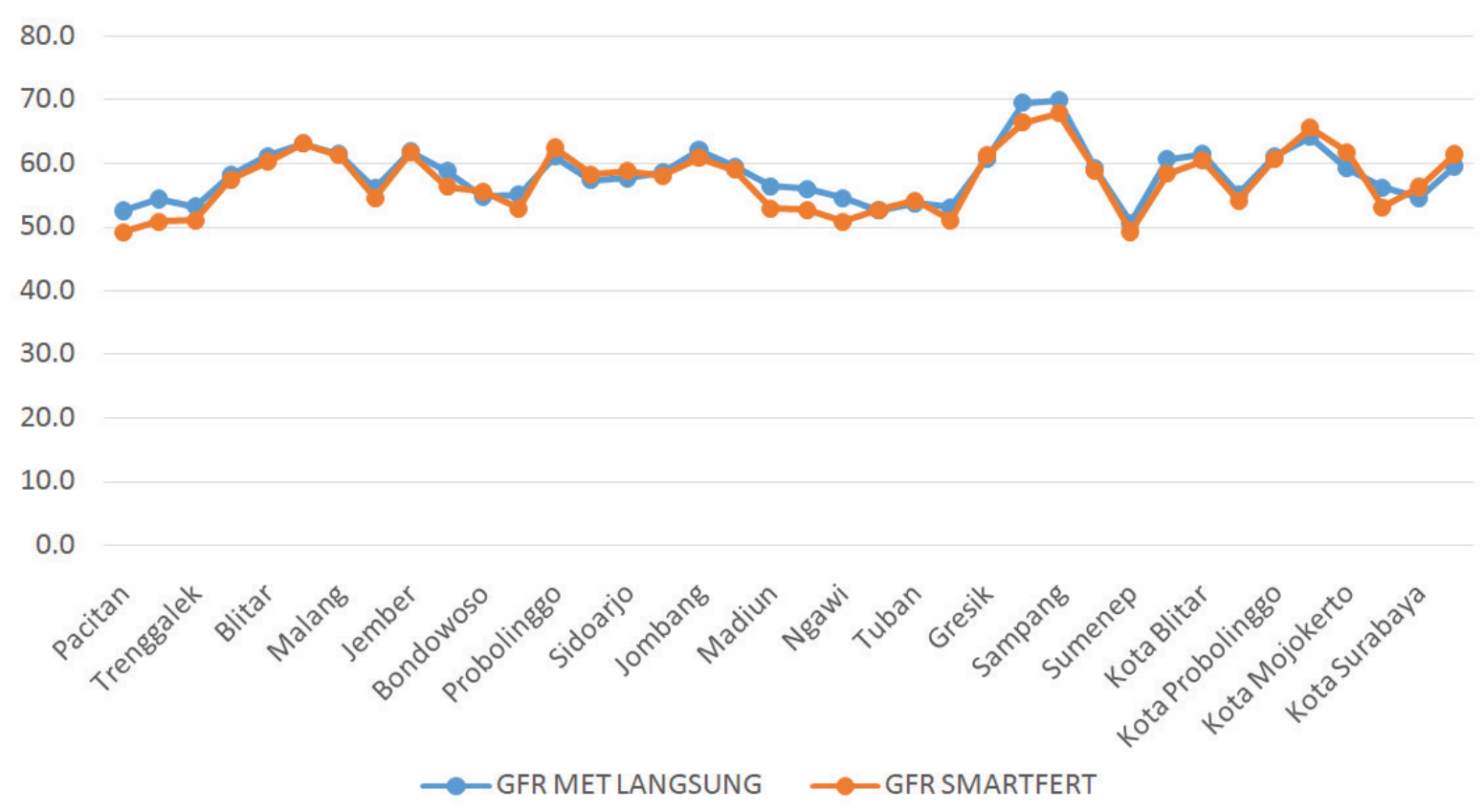

Gambar 3 GFR Hasil Olahan Smart Fert dan Sensus Penduduk 2010 
Tabel 2 GFR Hasil Olahan Aplikasi Smart Fert dan Sensus Penduduk 2010

\begin{tabular}{|c|c|c|c|c|}
\hline & Kab/Kota & $\begin{array}{c}\text { GFR } \\
\text { Metode Langsung } \\
\text { (Data SP 2010) }\end{array}$ & $\begin{array}{c}\text { GFR } \\
\text { Metode Asosiasi dengan } \\
\text { Aplikasi Smart Fert } \\
\text { (Data SP 2010) } \\
\end{array}$ & Selisih \\
\hline & Kabupaten & & & \\
\hline 1 & Pacitan & 52,6 & 49,2 & 3,4 \\
\hline 2 & Ponorogo & 54,4 & 50,9 & 3,5 \\
\hline 3 & Trenggalek & 53,2 & 51,1 & 2,1 \\
\hline 4 & Tulungagung & 58,2 & 57,5 & 0,7 \\
\hline 5 & Blitar & 61,1 & 60,3 & 0,8 \\
\hline 6 & Kediri & 63,1 & 63,2 & $-0,1$ \\
\hline 7 & Malang & 61,5 & 61,3 & 0,2 \\
\hline 8 & Lumajang & 56,1 & 54,5 & 1,6 \\
\hline 9 & Jember & 61,9 & 61,8 & 0,1 \\
\hline 10 & Banyuwangi & 58,8 & 56,3 & 2,5 \\
\hline 11 & Bondowoso & 54,8 & 55,6 & $-0,7$ \\
\hline 12 & Situbondo & 55,1 & 53,0 & 2,1 \\
\hline 13 & Probolinggo & 61,1 & 62,5 & $-1,4$ \\
\hline 14 & Pasuruan & 57,3 & 58,3 & $-1,0$ \\
\hline 15 & Sidoarjo & 57,7 & 58,9 & $-1,1$ \\
\hline 16 & Mojokerto & 58,6 & 58,1 & 0,5 \\
\hline 17 & Jombang & 62,1 & 61,0 & 1,2 \\
\hline 18 & Nganjuk & 59,5 & 59,0 & 0,5 \\
\hline 19 & Madiun & 56,4 & 53,0 & 3,5 \\
\hline 20 & Magetan & 56,1 & 52,7 & 3,4 \\
\hline 21 & Ngawi & 54,6 & 50,8 & 3,7 \\
\hline 22 & Bojonegoro & 52,6 & 52,8 & $-0,2$ \\
\hline 23 & Tuban & 53,8 & 54,2 & $-0,5$ \\
\hline 24 & Lamongan & 53,1 & 51,0 & 2,1 \\
\hline 25 & Gresik & 60,7 & 61,3 & $-0,7$ \\
\hline 26 & Bangkalan & 69,5 & 66,5 & 2,9 \\
\hline 27 & Sampang & 69,9 & 67,9 & 2,0 \\
\hline 28 & Pamekasan & 59,2 & 58,9 & 0,3 \\
\hline \multirow[t]{2}{*}{29} & Sumenep & 50,7 & 49,3 & 1,4 \\
\hline & Kota & & & \\
\hline 30 & Kota Kediri & 60,6 & 58,5 & 2,2 \\
\hline 31 & Kota Blitar & 61,5 & 60,4 & 1,0 \\
\hline 32 & Kota Malang & 55,2 & 54,2 & 1,0 \\
\hline 33 & Kota Probolinggo & 61,2 & 60,8 & 0,4 \\
\hline 34 & Kota Pasuruan & 64,1 & 65,7 & $-1,6$ \\
\hline 35 & Kota Mojokerto & 59,2 & 61,8 & $-2,7$ \\
\hline 36 & Kota Madiun & 56,2 & 53,1 & 3,1 \\
\hline 37 & Kota Surabaya & 54,6 & 56,3 & $-1,7$ \\
\hline \multirow[t]{2}{*}{38} & Kota Batu & 59,5 & 61,5 & $-1,9$ \\
\hline & JATIM & 58,0 & 57,0 & 1,0 \\
\hline
\end{tabular}

Sumber: Data primer, 2013 
Berdasarkan uji t-test untuk membedakan antara GFR hasil Smart Fert dengan GFR metode langsung data Sensus Penduduk di 38 kabupaten/kota di Jawa Timur, didapatkan hasil tidak signifikan (Sig. $=0,423$ ). Dengan demikian, diketahui bahwa tidak ada perbedaan signifikan antara kedua metode perhitungan GFR.

Hasil Perhitungan Angka Kelahiran Kasar (Crude Birth Rate/CBR)

Salah satu faktor yang ikut berperan dalam penghitungan angka pertumbuhan penduduk adalah kelahiran (fertilitas). Untuk mengetahui tingkat kelahiran hidup, antara lain, digunakan rumus CBR, yaitu banyaknya kelahiran hidup pada setiap seribu penduduk.

Bila menggunakan metode langsung, maka CBR dihitung dari jumlah kelahiran dibagi 1.000 penduduk. Perlu diketahui bahwa sampai saat ini pelaporan rutin mengenai jumlah kelahiran setiap tahunnya belum baik. Dalam metode tidak langsung, CBR di aplikasi Smart Fert ini dihitung dengan menggunakan metode asosiasi.

CBR dari olahan kedua metode dapat dilihat pada Gambar 4.

25.000

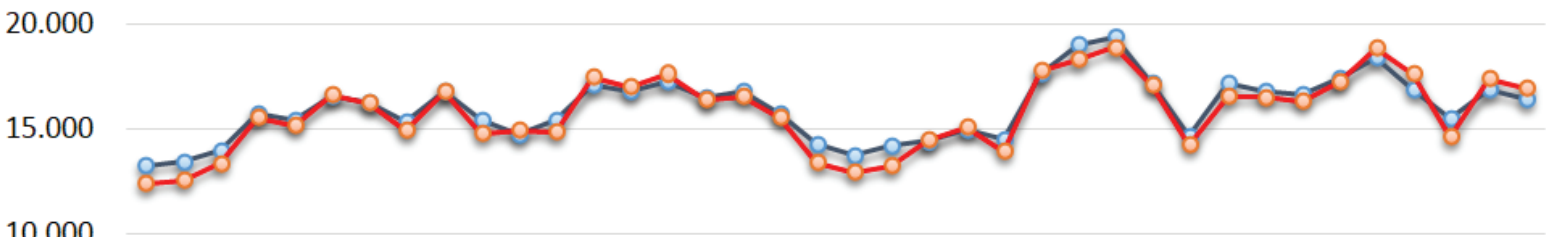

10.000

5.000

0.000

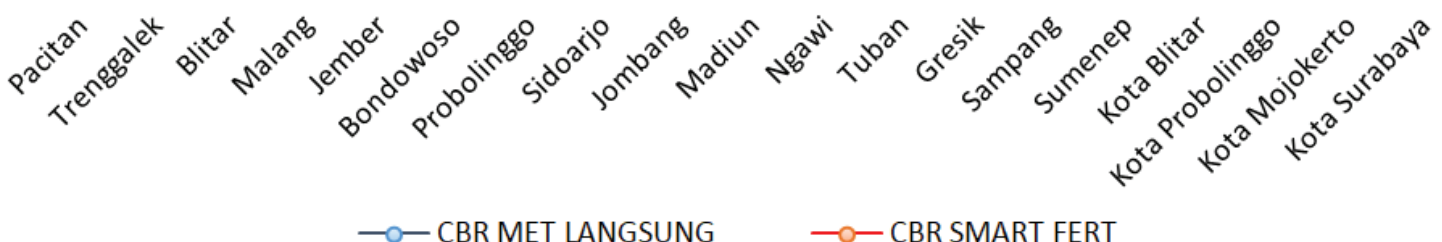

Gambar 4 CBR Hasil Olahan Smart Fert dan Sensus Penduduk 2010 
Tabel 3 CBR Hasil Olahan Aplikasi Smart Fert dan Sensus Penduduk 2010

\begin{tabular}{|c|c|c|c|c|}
\hline & Kab/Kota & $\begin{array}{c}\text { CBR } \\
\text { Metode Langsung } \\
\text { (Data SP 2010) }\end{array}$ & $\begin{array}{c}\text { CBR } \\
\text { Metode Asosiasi dengan } \\
\text { Aplikasi Smart Fert } \\
\text { (Data SP 2010) }\end{array}$ & Selisih \\
\hline & Kabupaten & & & \\
\hline 1 & Pacitan & 13,263 & 12,407 & 0,856 \\
\hline 2 & Ponorogo & 13,456 & 12,588 & 0,868 \\
\hline 3 & Trenggalek & 13,930 & 13,383 & 0,547 \\
\hline 4 & Tulungagung & 15,760 & 15,586 & 0,174 \\
\hline 5 & Blitar & 15,428 & 15,218 & 0,210 \\
\hline 6 & Kediri & 16,594 & 16,626 & $-0,032$ \\
\hline 7 & Malang & 16,301 & 16,254 & 0,047 \\
\hline 8 & Lumajang & 15,351 & 14,934 & 0,417 \\
\hline 9 & Jember & 16,813 & 16,784 & 0,029 \\
\hline 10 & Banyuwangi & 15,457 & 14,801 & 0,656 \\
\hline 11 & Bondowoso & 14,749 & 14,958 & $-0,209$ \\
\hline 12 & Situbondo & 15,462 & 14,860 & 0,602 \\
\hline 13 & Probolinggo & 17,091 & 17,486 & $-0,395$ \\
\hline 14 & Pasuruan & 16,783 & 17,070 & $-0,287$ \\
\hline 15 & Sidoarjo & 17,275 & 17,626 & $-0,351$ \\
\hline 16 & Mojokerto & 16,514 & 16,401 & 0,113 \\
\hline 17 & Jombang & 16,840 & 16,575 & 0,265 \\
\hline 18 & Nganjuk & 15,728 & 15,601 & 0,127 \\
\hline 19 & Madiun & 14,284 & 13,407 & 0,877 \\
\hline 20 & Magetan & 13,749 & 12,933 & 0,816 \\
\hline 21 & Ngawi & 14,215 & 13,260 & 0,955 \\
\hline 22 & Bojonegoro & 14,391 & 14,472 & $-0,081$ \\
\hline 23 & Tuban & 14,987 & 15,119 & $-0,132$ \\
\hline 24 & Lamongan & 14,517 & 13,975 & 0,542 \\
\hline 25 & Gresik & 17,628 & 17,821 & $-0,193$ \\
\hline 26 & Bangkalan & 19,063 & 18,318 & 0,745 \\
\hline 27 & Sampang & 19,470 & 18,924 & 0,546 \\
\hline 28 & Pamekasan & 17,190 & 17,145 & 0,045 \\
\hline \multirow[t]{2}{*}{29} & Sumenep & 14,669 & 14,278 & 0,391 \\
\hline & Kota & & & \\
\hline 30 & Kota Kediri & 17,183 & 16,564 & 0,619 \\
\hline 31 & Kota Blitar & 16,821 & 16,541 & 0,280 \\
\hline 32 & Kota Malang & 16,639 & 16,347 & 0,292 \\
\hline 33 & Kota Probolinggo & 17,400 & 17,292 & 0,108 \\
\hline 34 & Kota Pasuruan & 18,414 & 18,872 & $-0,458$ \\
\hline 35 & Kota Mojokerto & 16,888 & 17,653 & $-0,765$ \\
\hline 36 & Kota Madiun & 15,503 & 14,635 & 0,868 \\
\hline 37 & Kota Surabaya & 16,853 & 17,404 & $-0,551$ \\
\hline \multirow[t]{2}{*}{38} & Kota Batu & 16,452 & 16,980 & $-0,528$ \\
\hline & JATIM & 16,107 & 15,766 & 0,341 \\
\hline
\end{tabular}

Sumber: Data primer, 2013 
Berdasarkan uji t-test untuk membedakan antara CBR hasil Smart Fert dengan CBR metode langsung data Sensus Penduduk di 38 kabupaten/kota di Jawa Timur, didapatkan hasil tidak signifikan (Sig. $=0,575)$. Hal ini berarti tidak ada perbedaan signifikan antara kedua metode perhitungan CBR.

\section{Kesimpulan dan Saran}

Kesimpulan dari penelitian ini adalah aplikasi Sistem Informasi Fertilitas Smart Fert dapat dipakai sebagai alat pengukur fertilitas yang valid, praktis, dan mudah diimplementasikan di tingkat kabupaten/kota, bahkan di tingkat kecamatan sesuai dengan input data yang ada. Data yang tersedia dan indikator yang dihasilkan Smart Fert dapat tersedia setiap tahun tanpa menunggu hasil Sensus Penduduk setiap sepuluh tahun sekali. Aplikasi Smart Fert valid karena setelah diuji tingkat kesesuaian dengan hasil Sensus Penduduk 2010, didapatkan tidak ada perbedaan hasil yang signifikan.

Saran yang direkomendasikan adalah perlunya integrasi indikator fertilitas dalam perencanaan pembangunan daerah, seperti RPJMD. Dengan integrasi indikator fertilitas ke dalam RPJMD, maka dapat dipastikan Program Kependudukan dan KB menjadi bagian penting serta strategis dalam pelaksanaan pembangunan di daerah. Hal itu karena program tersebut mendapat alokasi anggaran yang memadai dari Anggaran Pembangunan dan Belanja Daerah (APBD). Dengan demikian, sinergitas dan keberlangsungan pembangunan berwawasan kependudukan akan terjamin. Di samping itu, diperlukan juga adanya panduan teknis tentang integrasi indikator fertilitas dalam perencanaan pembangunan dan teknik perhitungannya sehingga akan memudahkan bagi perencana dan pelaksana program kependudukan di kabupaten/kota. Di dalam panduan tersebut, perlu dijelaskan berbagai teknik perhitungan fertilitas, baik metode langsung maupun metode tidak langsung, serta pengenalan aplikasi fertilitas, termasuk aplikasi Smart Fert yang terbukti valid, simpel, dan mudah diimplementasikan.

\section{Daftar Pustaka}

Barclay, G. W.1970. Technique of Population Analysis, New York: John Willey \& Sons Inc.

Bogue, D. J. 1971. Demographic Techniques of Fertility Analysis, Community and Family Study Centre University of Chicago.

Iskandar. 1977. Demografi Teknik. Jakarta: Lembaga Demografi Fakultas Ekonomi Universitas Indonesia.

Jogiyanto. 2005. Analisis dan Desain Sistem Informasi, Pendekatan Terstruktur, Teori dan Praktik Aplikasi Bisnis. Yogyakarta: CV Andi Offset.

Jogiyanto,. 2009. Sistem Teknologi Informasi. Edisi III. Yogyakarta: CV Andi Offset.

Kasto. 1995. Handout TeknikDemografi.Yogyakarta: Program Studi Kependudukan UGM.

Lee-Jay Cho, R. D. R. and Choe, M. Ki. 1986. The Own Children Method of Fertility Estimation. Honolulu: East West Centre.

Lembaga Demografi. 1981. Dasar-Dasar Demografi. Jakarta: Lembaga Demografi Fakultas Ekonomi Universitas Indonesia.

Nilakusmawati, D. P. E. 2009. Matematika Populasi. Denpasar: Udayana University Press.

UN. 2003. Mortpak For Windows. New York: Population Devision Depart of Economic and Social Affairs UN.

UN Manual IV. 1967. Methods of Estimating Basic Demographic Measures From Incomplete Data. New York: United Nations.

UN Manual X. 1983. Indirect Technique For Demographic Estimation. New York: United Nations.

Yakub. 2012. Pengantar Sistem Informasi. Yogyakarta: Graha IImu. 